\title{
Social support in the practices of informal providers: The case of patent and proprietary medicine vendors in Nigeria
}

\author{
Maia Sieverding ${ }^{\text {** }}$, Jenny Liu ${ }^{a}$, Naomi Beyeler ${ }^{a}$ \\ ${ }^{a}$ Global Health Sciences, University of California, San Francisco \\ *Corresponding author \\ $55016^{\text {th }}$ Street, $3^{\text {rd }}$ Floor \\ San Francisco, CA, 94158 \\ Maia.Sieverding@ucsf.edu \\ Tel: +1-415-476-5592 \\ Fax: $+1-415-476-5348$
}

Acknowledgements: We thank our dedicated field team, without whom this study would not have been possible. The anonymous reviewers provided very helpful comments. The Society for Family Health in Nigeria provided logistical support for the research. This study was funded by a grant from the Bill and Melinda Gates Foundation. 


\section{Abstract}

2 The social and institutional environments in which informal healthcare providers operate shape

3 their health and business practices, particularly in contexts where regulatory enforcement is

4 weak. In this study, we adopt a social capital perspective to understanding the social networks on

5 which proprietary and patent medicine vendors (PPMVs) in Nigeria rely for support in the

6 operation of their shops. Data are drawn from 70 in-depth interviews with PPMVs in three states,

7 including interviews with local leaders of the PPMV professional association. We find that

8 PPMVs primarily relied on more senior colleagues and formal healthcare professionals for

9 informational support, including information about new medicines and advice on how to treat

10 specific cases of illness. For instrumental support, including finance, start-up assistance, and

11 intervention with regulatory agencies, PPMVs relied on extended family, the PPMVs with whom

12 they apprenticed, and the leaders of their professional association. PPMVs' networks also

13 provided continual reinforcement of what constitutes good PPMV practice through

14 admonishments to follow scope of practice limitations. These informal reminders, as well as

15 monitoring activities conducted by the professional association, served to reinforce PPMVs'

16 concern with avoiding negative customer health outcomes, which were perceived to be

17 detrimental to their business reputations. That PPMVs' networks both encouraged practices to

18 reduce the likelihood of poor health outcomes, and provided advice regarding customers' health

19 conditions, highlights the potential impact of informal providers' access to different forms of

20 social capital on their delivery of health services, as well as their success as microenterprises.

21 Keywords: Nigeria; medicine vendors; social support; provider reputation; professional

22 associations 


\section{Introduction}

25 Due to the limited capacity of health systems in many low- and middle-income countries

26 (LMICs), there has been growing interest in the role of private, informal providers in filling gaps

27 in health services delivery. Informal providers span a variety of retail and practitioner types,

28 including drug shops, private clinics, midwives and traditional birth attendants, and traditional

29 healers practicing in a range of medical traditions (Bloom et al., 2011; Sudhinaraset et al., 2013).

30 Although a variety of definitions exist for what 'informal' means in the context of health service

31 provision, most definitions agree that informal providers are those who perform services for

32 which they have not received formal training, and who in some way operate outside of

33 established regulatory boundaries (Bloom et al., 2011; Sudhinaraset et al., 2013). Whether those

34 regulatory boundaries recognize informal providers at all, or whether the providers are operating

35 outside the bounds of their legal regulatory scope, is heavily context- and time-dependent (Cross

36 and MacGregor, 2010). Yet the limited data available suggest that informal providers constitute

37 over half of all healthcare providers in some LMICs (Sudhinaraset et al., 2013). Their practices

38 therefore have broad implications for access to and quality of healthcare in many contexts.

40 Numerous studies have documented the characteristics, utilization, and quality of service of

41 informal providers (for reviews, see Shah et al., 2011; Sudhinaraset et al., 2013; Wafula et al.,

42 2012). Yet it is informal providers' location on the "margins of legitimacy" (Cross and

43 MacGregor, 2010, p. 1594) that has sparked the most debate about how to work with this sector

44 of the health system. Standard economic approaches focus on the profit motive of private

45 healthcare providers, arguing that this may lead to excess or inappropriate provision of services

46 (Arrow, 1963; Sloan, 2000). The assumption of self-interested profit maximization has been 
47 widespread in the literature on informal providers, particularly given that many operate in

48 contexts where regulatory enforcement is weak (Bloom et al., 2008; Cross and MacGregor,

49 2010). Recently, several scholars have challenged this narrow conception of provider

50 motivations, arguing that the tenuous position of informal providers in relation to formal

51 regulatory structures leads to a broader range of influences on their practices. These scholars

52 have pointed out that informal providers are socially embedded actors whose practices are

53 influenced by their relationships with their host communities, position within professional

54 networks, and ties to formal institutions, in addition to economic incentives (Bloom et al., 2008;

55 Cross and MacGregor, 2010; George and Iyer, 2013). Greater contextualization of informal

56 providers within the social and institutional environments in which they function is therefore key

57 to understanding their practices.

59 However, few studies have explored how informal providers relate to social and institutional

60 structures in specific empirical contexts. Those that have suggest that informal providers rely on

61 a range of professional networks in different aspects of their practices. In India, rural medical

62 practitioners (RMPs) have been found to maintain ties to the providers under which they

63 apprenticed (George and Iyer, 2013), and to rely on referral relationships with other providers as

64 means of continued learning (Ecks and Basu, 2014; George and Iyer, 2013). Village doctors in

65 Bangladesh and RMPs in India obtain information about medicines from drug detailers (Ecks

66 and Basu, 2014; Rahman et al., 2009, cited in Bloom et al. 2011). Several studies have also noted

67 that different types of informal providers self-organize through professional associations (Ecks

68 and Basu, 2014; George and Iyer, 2013; Sudhinaraset et al., 2013). Although studies of these 
69 associations are few, one exception is the association of patent medicine dealers in Nigeria,

70 which we discuss in greater detail below.

72 The small number of studies on informal providers' network resources is particularly surprising

73 given the broader interest within the development literature in the role of social networks and

74 social capital in entrepreneurial development. We follow Woolcock in defining social capital as

75 the "information, trust and norms of reciprocity inhering in one's social networks" (1998, p.

76 153). Norms of reciprocity in turn entail the "exchange of social support," (Ferlander, 2007, p.

77 116) where support is typically categorized as being of four types. Emotional support is the

78 provision of caring or empathy, whereas instrumental support entails the provision of concrete

79 forms of assistance such as finance. Two additional types, related to information, are

80 informational support, the provision of advice or information that helps individuals to manage

81 situations they encounter, and appraisal support, which is the provision of information that

82 specifically helps the recipient to self evaluate their own performance or behavior (House, 1981).

83

84 In Sub-Saharan Africa, a social capital framework has been applied to the study of several types

85 of micro-entrepreneurs (Barr, 2000; Fafchamps and Minten, 2002; Lyon, 2000; Zuwarimwe and

86 Kirsten, 2010), pointing to both the effects and the nature of these entrepreneurs' social

87 networks. This literature finds that larger and more diverse networks lead to higher enterprise

88 productivity (Barr, 2000; Fafchamps and Minten, 2002), and that small entrepreneurs rely on

89 their networks both to stabilize their income (Lyon, 2000) and to expand their businesses

90 (Zuwarimwe and Kirsten, 2010). The networks on which micro-entrepreneurs rely to achieve

91 these outcomes in rural Sub-Saharan African contexts are both formal (e.g. associations) and 
92 informal (e.g. friends, family and acquaintances) in nature (Lyon, 2000; Zuwarimwe and Kirsten,

93 2010; see also Ferlander, 2007). This differentiation of the formality of entrepreneurs' networks

94 is distinct from the common categorization of social capital as bonding, bridging or linking.

95 Bonding social capital exists between network members that are similar in terms of their socio-

96 demographic characteristics, whereas bridging social capital exists between members who are

97 dissimilar from one another but are linked through a horizontal (egalitarian) relationship (Szreter

98 and Woolcock, 2004; Ferlander, 2007). Linking social capital connects people across explicit

99 social or institutional power differentials; for example, a healthcare provider and her patient. The

100 presence of respectful, collaborative (as opposed to extractive or suppressive) linking social

101 capital has been argued to be key for service delivery in a range of fields, including health, to

102 effectively meet the needs of the beneficiary population (Szreter and Woolcock, 2004). The

103 overlap between these forms of social capital and network formality can be useful in

104 understanding how micro-entrepreneurs receive different forms of support, a point we return to

105 in the discussion.

107 None of these previous studies on micro-entrepreneurs in Sub-Saharan Africa, however, address

108 entrepreneurs in the health sector. In this study, we apply a social capital perspective to

109 understand the professional networks of proprietary and patent medicine vendors (PPMVs) in

110 Nigeria. PPMVs are owner-operated retail drug shops that are ubiquitous throughout Nigeria,

111 with an estimated 200,000 in the country (Barnes et al., 2008). Although legal and regulated by

112 the Ministry of Health (Barnes et al., 2008), PPMVs are not required to have formal training in

113 pharmacy or medicine and typically complete an apprenticeship with a more senior PPMV prior

114 to opening their shop (Beyeler et al., 2015; Brieger et al., 2004). Although only primary 
115 education is required to open a PPMV, recent studies indicate that the majority hold at least a

116 secondary degree and substantial percentages in fact have formal medical training (Beyeler et al.,

117 2015). Nevertheless, there are significant concerns about the quality of service provided by this

118 highly diverse sector (Beyeler et al., 2015), and studies indicate that compliance with scope of

119 practice regulations (Fajola et al., 2011; Ujuju et al., 2014) and licensing requirements is low

120 (Beyeler et al., 2015; Oyeyemi et al., 2014). These concerns about the quality of care provided

121 by PPMVs, and the role of their social networks in influencing their practices, is significant

122 given that PPMVs are a major source of care in the country, particularly among poor and rural

123 communities (Onwujekwe et al., 2011).

124

125 Lack of regulatory enforcement does not mean that the PPMV sector is unorganized; PPMVs

126 have a professional association, the Nigerian Association of Proprietary and Patent Medicine

127 Dealers (NAPPMED) that operates at multiple administrative levels, with branches extending

128 from a national body down to the state, Local Government Area, and local (ward) levels

129 (Oladepo et al., 2007). To our knowledge, only one study has examined the functioning of

130 NAPPMED, which was based on interviews with leaders of 12 local association chapters

131 (Oladepo et al., 2007). These leaders reported that NAPPMED provides opportunities for

132 members to improve their knowledge, helps with problems, and defends members' interests, and

133 that NAPPMED fines members for practices deemed inappropriate, such as selling unapproved

134 drugs or failing to attend NAPPMED meetings. The association also has relationships with local

135 government and regulatory officials, whom they deal with to resolve members' problems

136 (Oladepo et al., 2007). How member PPMVs who are not part of the leadership view

137 participation in NAPPMED, and the contexts in which they rely on the association for support, 
138 has not been explored. Other social networks, including informal networks of personal and

139 professional contacts, which PPMVs may rely on in running their shops, have also not been

140 investigated.

141

142 Our objective in this study is to understand how and why PPMVs access different forms of social

143 capital that may influence their health and business practices. Specifically, we (1) describe the

144 characteristics of the social networks that PPMVs rely on for support related to both the health

145 and business aspects of their shops, (2) explain the forms of support that PPMVs receive and

146 situate these within common categorizations of social support, and (3) explain why PPMVs rely

147 on certain types of network contacts for different forms of support. In addressing the last

148 objective, we pay particular attention to when and why PPMVs call on NAPPMED as compared

149 to other contacts. In conclusion, we consider the implications of our findings in terms of the

150 importance of social capital to microenterprises that provide health services.

151

\section{Methods}

153 The data for this study are drawn from in-depth interviews with PPMVs in rural areas of Kogi

154 and Kwara states in North Central Nigeria and Enugu state in the South East. Kogi and Kwara

155 states were selected based on the relative lack of research on PPMVs in the North-Central region,

156 and Enugu was chosen as a comparison and validation site because much of the existing

157 literature on PPMVs comes from the South East region (Beyeler et al., 2015). The qualitative

158 interviews were part of a larger mixed-methods study of the role of PPMVs in providing

159 pediatric care. 
162 We adopted a purposive sampling approach that followed the organizational structure of

163 NAPPMED. This strategy was adopted because no sampling frame for PPMVs was available for

164 the study states at the time, and because a sampling strategy based on the organization of

165 NAPPMED allowed for the inclusion of multiple members and leaders of each NAPPMED unit

166 into the study, enabling a broader examination of the strength and nature of linkages between the

167 actors within a unit. Statistical representativeness was not an explicit aim of the study. In each

168 state, we selected one Local Government Area (LGA), within which we selected two to three

169 wards, the smallest administrative unit and the level at which most PPMVs attend regular

170 NAPPMED meetings. In consultation with local NGOs and state-level NAPPMED leaders, we

171 selected wards that were primarily rural, but varied in terms of health services available and

172 distance from urban centers.

173

174 In each ward, we met with the head of the local NAPPMED chapter to gather information about

175 the shop locations of members. With the local data collection team, we also gathered information

176 on available health services at the village level and identified PPMV shops that may not have

177 been registered with NAPPMED. Based on this information, we selected four to eight villages in

178 each ward for data collection that varied according to the number of PPMV shops, the presence

179 or absence of a public health center, and distance from the main road. The data collection

180 covered 30 villages: eight each in Kogi and Enugu, and 14 in Kwara. More villages were

181 included in Kwara due to the greater dispersion of the population and the addition of a third

182 ward.

183 
184 Within each selected village, we attempted to interview all PPMVs in order to capture the extent

185 to which PPMVs in the same geography are embedded in the same networks. Interviews were

186 only conducted with shop owners because apprentices and other shop staff were unable to

187 answer questions about shop operations during pre-testing. We interviewed between one and

188 nine PPMVs per village. Although few PPMVs refused to participate in the study, we were

189 unable to interview some PPMVs because the shop was closed or the owner was not present. As

190 statistical representativeness was not an aim of the study, we did not record refusals or calculate

191 a refusal rate. We conducted a total of 70 interviews (21 in Kogi, 29 in Kwara, and 20 in Enugu),

19210 of which were with the leadership of the ward- or LGA-level NAPPMED association,

193 primarily the chairman or vice-chairman.

195 Data collection

196 Interviews were conducted in August 2013 by local staff recruited by a local Non-Governmental

197 Organization in each state and trained by the first and third authors. A different field team

198 conducted interviews in each state due to language differences; interviews were conducted in

199 Yoruba in Kwara, Igbo in Enugu, and either Pidgin English or Igala in Kogi. In order to ensure

200 reliability across teams, each interview team was trained using a standard three-day curriculum.

201 Data collection took four to six days in each state, and the entire period was supervised directly

202 by the authors, who monitored procedures and debriefed with field staff daily. Once this

203 feedback indicated that data saturation for the area had likely been reached, fieldwork moved to

204 the next site. Permission was sought from the village chief, and LGA- and ward-level

205 NAPPMED chairmen to conduct the study in their areas. Verbal informed consent was obtained

206 from all respondents prior to the interview. Interviews lasted 60 to 100 minutes; due to the length 
207 of the interviews, they were conducted in the respondent's shop so that s/he could continue to

208 attend to customers. Respondents were given a small gift valued at 500 Naira ( US\$3.13) for

209 their participation.

211 The interview guide was developed during pretesting in April and June 2013. Interviewers

212 followed a semi-structured guide that included questions about whom PPMVs called on for three

213 main domains of social support: information about medicines; support when encountering a

214 difficult pediatric case; and support when faced with a problem in the shop. These three domains

215 were selected because of their importance for both the health care services that PPMVs provide

216 and the business operations of their shops. Basic information on the first three contacts

217 respondents named in each domain was recorded in tabular format for purposes of comparison.

218 The interviews then included a series of follow-up questions that probed why respondents turned

219 to these specific contacts for help, advice or information, what kind of advice or help they

220 usually received, and the content of the his/her last conversation with the contact. Interviews also

221 covered PPMVs' business operations, scope of practice, participation in NAPPMED, and

222 perception of their role as a PPMV compared to that of formal health providers. The study

223 received ethical approval from the University of California San Francisco and the National

224 Health Research Ethics Committee of Nigeria.

226 Data analysis

227 Interviews were digitally recorded in the field. A local team for each language then

228 simultaneously translated the interviews into English and transcribed them. A random selection

229 of interviews in each language group was back-checked for translation and transcription 
230 accuracy before the files were transferred to the authors for analysis. As all of the transcripts

231 were translated into non-standard English, the quotes presented have been edited for

232 comprehension. Village and other proper names have been removed or anonymized to preserve

233 confidentiality.

235 We conducted the qualitative analysis in Atlas.ti using an open coding approach; codes and sub236 codes were derived from the data rather than determined a priori. We adopted an iterative

237 approach to developing the codebook; each author coded several transcripts and developed a list

238 of codes, which we then merged and reconciled, refining code definitions and hierarchies. We

239 repeated this process several times until only minor adjustments to the codebook resulted. The

240 analysis in this paper primarily relies on the code families related to accessing social support in

241 the three main domains of interest. We supplement this with codes related to respondents'

242 personal and professional connections to local health facilities, their experiences starting up their

243 shop, and perceived benefits and requirements of participation in NAPPMED. The coding

244 process indicated that data saturation was reached, as very few modifications to the codebook

245 were made as we coded the later interviews.

247 Results

248 Characteristics of PPMVs and their support networks

249 Of the 70 PPMVs who participated in the study, 68 of whom answered the network questions

250 collected in tabular form, the large majority $(\mathrm{n}=57)$ had at least a secondary education (Table 1$)$.

251 Nineteen of the respondents also had some form of formal medical training; most of these were

252 community health workers and a small number were trained as nurses or midwives. Nearly forty 
253 percent $(\mathrm{n}=26)$ of the respondents were female. All but one respondent reported being a current

254 member of NAPPMED.

256 On average, respondents listed a greater number of contacts they would call upon to learn about

257 a new medicine (1.8 contacts) than in the domains of a difficult pediatric case or a problem in the

258 shop (Table 2). The most common type of contact named for obtaining information about new

259 medicines were other PPMVs (38\%) and other drug retailers or wholesalers (36\%) including

260 pharmacists, followed by medical professionals (23\%) including nurses, doctors, and other health

261 workers. No PPMVs listed pharmaceutical representatives or drug detailers as a contact in this or

262 the other domains. Nearly $80 \%$ of these contacts lived outside the respondents' community. In

263 contrast, for advice on a difficult pediatric case, $60 \%$ of the contacts that respondents named

264 were medical professionals. An additional $32 \%$ of contacts were other PPMVs; very few

265 respondents named other types of contact for support in this area. A higher percentage of the

266 contacts named for medical advice (43\%) also resided in the same community as the respondent.

267 Overall, however, respondents reported a smaller average number of contacts in this domain

268 (1.3); this was due to the higher percentage of respondents who did not list any specific contacts,

269 most of whom said that they always referred difficult pediatric cases.

271 The main problems PPMVs reported experiencing in their shops were financial difficulties and

272 encounters with regulatory authorities. When experiencing these problems, respondents

273 primarily relied on other PPMVs (46\% of contacts) or informal networks of personal contacts

274 (32\%), including family members, landlords, and community leaders. Among the other PPMVs

275 that respondents named, the local NAPPMED chairman featured more prominently than for 
276 other kinds of assistance; $19 \%$ of contacts named for a problem in the shop were the chairman,

277 compared to $8 \%$ for information on medicines and $6 \%$ for a difficult case. As compared to the

278 other two domains, relatively few contacts named for dealing with a problem in the shop were

279 medical professionals (14\%). Across these domains, as well as in respondents' discussions of

280 how and why they received this support (presented below), we did not find any consistent

281 differences in respondents' networks by socio-demographics, including gender and ethnicity, or

282 by state.

283

$284 \quad$ Forms and sources of support

285 We now turn to a description and categorization of the types of support that respondents reported

286 receiving in these domains of running their shop. Informational and instrumental support

287 emerged as the most common types, but we also discuss a third form of support, reputational

288 support, which is related to appraisal support but also served a broader purpose of protecting the

289 PPMV profession as a whole.

290

291 1. Informational support

292 Respondents described receiving a wide range of informational support, particularly in the

293 domains of their shop operations that related to health practices. For some operational needs,

294 such as drug supply, respondents primarily relied on their contacts to gain information on

295 products and their uses. However, when dealing with the cases of specific customers, they often

296 described more extended interactions centering on advice and problem-solving. 
300 Respondents described collecting different types of information about new drugs from their

301 contacts, including the uses of new drugs, dosages and administration, explanations of label

302 information, and advice on drug efficacy. Less frequently, respondents described asking their

303 contacts about new medications that they had heard about through the media but did not fully

304 understand. Several also described seeking information about the comparative affordability and

305 efficacy of drugs that were substitutes for one another.

307 The majority of contacts that respondents relied on to learn about drug information were other

308 drug retailers or wholesalers. In a context where supply chains are informal and highly variable,

309 respondents indicated that the pharmacists, wholesalers, distributors, and even PPMVs with

310 larger shops from whom they procured their stock were important contacts because they had

311 more up-to-date information than PPMVs located in villages. Suppliers located in urban

312 locations had closer ties to main distribution centers and stocked a wider variety of products.

313 Respondents also stated that they asked their pharmacist contacts about new drugs because of

314 their more extensive training and perceived greater knowledge of pharmaceuticals.

316 [He] is a dealer, he goes to Onitsha and to Lagos [large drug markets]. At times, 317 companies will come down to his shop with a new medicine and introduce the new 318 medicine to him. Anytime that I go there I will seek advice, maybe he will tell me 319 that this [drug] is working for this, this [drug] is working for this. - PPMV and 320 NAPPMED leader, Achem village, Kogi 
He is a pharmacist and he sells drug to us. If we see a new drug that is strange to

323

324

325

326

327 Respondents' reliance on these drug supply networks likely explains why a large percentage of

328 their contacts for drug information lived outside their own communities.

330 Respondents who sought information on drugs from fellow PPMVs typically did so from those

331 who were more senior to them, including their "master," or the PPMV with whom they

332 apprenticed. They often cited these colleagues' greater experience, as well as respect for elders in 333 this line of work, as the reason. They say the best teacher is the experienced person. Maybe out of experience, he knows more than I do about drugs. That is why I go to him as my master. PPMV, Ozonze village, Enugu 
346 As noted above, respondents were more likely to rely on medical professionals when faced with

347 difficult pediatric cases than in other domains. Respondents' interactions with these contacts also

348 appeared to be more consultative, involving advice, direction, and problem-solving. Respondents

349 who contacted medical professionals for advice did so out of recognition that doctors, nurses,

350 and other health practitioners had studied medicine formally, and were therefore more

351 knowledgeable about treating child illness. The very fact that contacts were doctors or nurses

352 was often given as the reason for contacting them, as explained by a PPMV in Enugu: "Why I go

353 to [Doctor X] is because he studied medicine...he knows what is wrong because he is a doctor."

355 In the study villages, where PPMVs and a public health center were often the only sources of

356 healthcare available, respondents knew many of these medical professionals as referral points as

357 well as sources of advice. Some PPMVs appeared to have close relationships with the local

358 medical professionals they called on for advice, whether through personal friendships, dual

359 employment in public health facilities (among medically trained PPMVs), or, in a few cases,

360 having apprenticed under a medical professional. As such, these relationships were informal

361 rather than established through the health system. ...sometimes when someone brings a child, [the local nurse] might be here, so he

364 will tell me to refer the customer to the hospital... Sometimes [the nurse] will say

365 that I should give the customer an anti-malarial, and when they use it, it will be

366 effective. - PPMV, Ayorinde village, Kwara, on a nurse at the local health facility 
I will call [Dr. X] and he will send for the person to be brought up to his place. Or he will tell me to give the person a certain drug. If I give the drug and [the sickness] doesn't subside, I will call [Dr. X] and tell him. He will then tell me to bring the person to his place so he will see the person himself. - PPMV, Onyinye

372 village, Enugu, on a medical doctor with whom he apprenticed

373 A few respondents also described situations in which they personally brought their clients to the

374 health facility if the client didn't have their own means of transportation, or intervened with 375 health facility staff to vouch for a client who could not readily pay for services. These more 376 extensive interactions around advice and referral help to explain why a larger percentage of

377 respondents' contacts in the domain of advice for difficult pediatric cases resided in the same 378 community.

380 For advice in dealing with specific cases, many respondents also called on other PPMVs,

381 oftentimes their master or a more senior PPMV, to obtain drug information. However, the advice 382 that respondents described receiving from other PPMVs commonly revolved around the specific 383 drugs to administer for difficult cases rather than when and to whom to refer. A small number of 384 respondents recounted receiving advice, for example to administer an injection, that was counter 385 to PPMVs' legal scope of practice. If they bring a child to me and I don't know [what to do], I will call my master... and he will advise me that "this is how you will do it, this is the type of drug you will give him" and if I don't have it he will ask me to refer [the child]. - PPMV, Iseyemi village, Kwara 
When I tell him that this is what is happening with the child I am treating, he will tell me to "give the child this injection," and that when I've given it to the child and he is better, I should add a certain medicine. - PPMV, Usman village, Kogi, on his master

397 Respondents again explained their reliance on other PPMVs for this type of support in

398 terms of senior PPMVs' greater knowledge and experience, and in some cases as a

399 continuation of their role as an apprentice.

401 2. Instrumental support

402 In addition to information, respondents relied on their contacts to provide them with tangible

403 forms of assistance when faced with difficult circumstances. Although this type of assistance

404 often pertained to the business operations of the PPMV shop, at times it extended into the

405 domain of health practices.

406

407 2a. Financial and start-up support

408 A number of respondents, particularly in Kogi and Kwara, mentioned facing cash flow shortages

409 in their shop. In these situations, they relied primarily on family members and sometimes on

410 fellow PPMVs to borrow money, often to restock their shop, which then enabled them to

411 continue earning a living. One respondent described the importance of informal sources of credit

412 for running his shop:

413 
If I do not have money to buy drugs, there is nobody that I can ask except for my wife and if she has [money], she will give me. Because when they [customers] come here and you say "[the drug] is not available," it means you are not serious with what you are doing.- PPMV, Kofoworola village, Kwara

419 Several respondents also mentioned purchasing stock from their suppliers on credit, which they 420 repaid the next time they restocked.

422 Most respondents reported receiving money from relatives, particularly parents and siblings,

423 when they opened their shop. Respondents also received financial and logistical assistance from

424 their masters when they transitioned from being an apprentice to owning their own shop. In 425 several cases, this assistance included help with licensing and providing an introduction and 426 reference to the local NAPPMED chapter. [My master] took me to Patent Medicine Dealers in this Local Government Area and told them that he taught me and he signed as the master for me. Then he took me to the market and bought me goods I will sell, and made a shelf for me, and paid for the shop and where I live. - PPMV, Ekwebelem village, Enugu

433 However, the degree of financial and non-financial start-up assistance provided by masters

434 varied substantially, which may result from the fact that start-up assistance is often a part of the 435 informal contract established between master and apprentice. At one extreme, a few respondents 436 reported that their master paid for and helped them set up their whole shop, or even left them an 
437 existing shop to run while the master went on to establish a new one. At the other, several

438 respondents said that they did not receive any financial or other start-up support from their

439 masters.

$4412 b$. Intervention with regulatory agencies

442 Respondents in the study areas felt vulnerable to harassment, detention, or drug seizures by local

443 regulatory or law enforcement authorities, who were perceived to be more motivated by

444 extracting bribes than enforcing regulations, although many respondents also acknowledged that

445 some PPMVs overstepped their legal scope of practice. In nearly all reported encounters with

446 regulatory or law enforcement agencies, respondents turned to their local NAPPMED leaders to

447 intervene.

448

449 As far as our union is concerned, he [the NAPPMED chairman] is the head. [If] I

450 have any embarrassment from anybody, I will call him... if I'm carrying medicine

451 and the police or any force sees me and asks me why I'm carrying medicine, I'll

452 tell them I'm a Patent Medicine Dealer, that I sell the medicine. If [the police]

453 refuses, I will call [the chairman], and he will come. - PPMV, Ekwebelem

454 village, Enugu, on the local NAPPMED Chairman

455

456 It is through the association [NAPPMED] that we can continue to run this

457 business without having any problems. And whenever we have a problem - like

458 sometimes when we are bringing drugs [for re-stocking] we get arrested by the

459 police - then our officials [NAPPMED leaders] go and get the drugs back for us. 
462 A few respondents also described how NAPPMED leaders would try to negotiate the "tax" that

463 external agencies would charge them, warn members that regulatory agencies were conducting

464 sweeps, or try to forestall shop visits by speaking with the agencies beforehand. Respondents'

465 reliance on NAPPMED to intervene with the authorities corresponded with their overall

466 depiction of the organization as their union. Most respondents viewed NAPPMED registration as

467 obligatory, and NAPPMED ward chapters regulated entry into the local market, approving who

468 could open a shop and where the shop could be located. As one respondent in Kogi stated, "you

469 cannot operate without a license, and you cannot operate without joining the union."

471 The frequency with which respondents turned to NAPPMED for support, and the types of

472 support they received, varied significantly across chapters depending on the engagement of the

473 executives. For example, in one chapter in Enugu that was highly active according to members'

474 descriptions, most respondents mentioned the local chairman as someone whom they would call

475 for help with a wide range of issues, including drug information, health advice, and regulatory

476 intervention. In such situations, the professional ties between respondents and their more senior

477 colleagues, including NAPPMED leaders, were overlaid with a personal dynamic of mentorship.

478 Respondents sometimes used familial language to describe their relationships with these senior

479 PPMVs who were "like a father" to them. However, there were other wards in which few or

480 none of the respondents reported asking NAPPMED leadership for either instrumental or

481 informational forms of support.

482 
484 A third form of support, which we term reputational support, emerged from respondents'

485 description of their network contacts and combined elements of informational and appraisal

486 support while also serving a broader collective function. Maintaining a good reputation was seen

487 as essential to running a successful PPMV shop, and was often understood by respondents in

488 terms of avoiding bad practices, i.e. a good reputation meant not doing what one was not

489 supposed to do as a PPMV. In one sense, avoiding practices outside PPMVs' legal scope was a

490 form of self-protection against regulatory enforcement. Yet more importantly, avoiding these

491 practices was also a means of guarding against poor customer outcomes, which were detrimental

492 for a PPMV's reputation and therefore for his business.

493

The primary health center does tests, they also set drips [IVs]. There are things they do that we can't do... if you [in the PPMV shop] set a drip, give blood or stitch a wound, tomorrow they [the community] may say that you are doing what they are supposed to do in the hospital. [Then] you are on your own, and you know it is a problem for you. - PPMV, Ndah village, Kogi

500 The distinguishing factor between reputational and the other forms of support was that

501 reputational support was not only about individual PPMVs, but also about protecting the 502 reputation of the professional as a whole.

503

504 At the individual level, reputational support consisted of general admonishments about the legal

505 limits of PPMV practice and the potential negative consequences of overstepping those limits. 
506 Respondents described their contacts of all professions, including fellow PPMVs, telling them

507 about what drugs not to stock in their shops, and many also described medical professionals

508 telling them not to touch complicated cases, to always refer, and not to administer certain kinds

509 of treatments (such as injections) that are beyond PPMVs' scope of practice. ....he tells me about all those banned drugs that I should not sell. He also advises me that any medicines that do not have NAFDAC number, I should not buy and sell them because all those NAFDAC and drug laws...can create problems PPMV, Ndah village, Kogi, on a pharmacist acquaintance

He tells me that I should be careful. He says that in the work of health, if there is

521 What distinguished these reminders from informational support was that they did not convey 522 specific knowledge or advice. Instead, they were general cautions intended to prevent negative 523 customer health outcomes that would in turn damage a PPMV's business. As such, respondents 524 understood these good practice reminders as a form of help that their contacts provided them in 525 order for them to do their job well.

527 The network of good practice reminders among PPMVs' informal contacts was formalized at the 528 level of the profession through NAPPMED's self-monitoring and enforcement mechanisms. As 
529 described by both members and leaders, NAPPMED meetings included frequent discussion of

530 what PPMVs should not do, including selling fake, expired or banned drugs, administering

531 injections, or treating cases that they did not know how to handle. The reinforcement of good

532 practice to avoid negative health outcomes was also part of how some leaders described the 533 association's aims. My responsibility is to keep my people [members] informed on what to do and what not to do. Under NAPPMED we have limitations, we have the things we can do and the things we cannot do, [so I] advise my members that if any case that they cannot handle comes across them, they should not try to handle it, because life has no duplicate... It can happen that a person comes to you with a problem, and then due to your ignorance you double the problem again [i.e. make the problem worse].- NAPPMED leader, Onojo village, Kogi

543 Most ward chapters also had a local "task force" that inspected members' shops for prohibited

544 drugs with varying degrees of frequency; if found, these were confiscated by the task force itself.

545 As portrayed by NAPPMED leaders and members, these mechanisms were intended to reduce

546 "embarrassments" caused by encounters with outside agencies.

$548 \quad$ The task force moves around making sure that everybody keeps their shop clean

549 [free from banned drugs]. Then, because we by ourselves have made it clean

550 before even NAFDAC or all these other agencies come, if any agency enters any

551 shop, they will see that we are okay. - NAPPMED leader, Mbanusi village, 
554 The purpose of self-monitoring activities, however, was not simply to evade detection by

555 regulatory agencies. Although members noted that dealing with punitive measures from

556 NAPPMED was easier than from external agencies, NAPPMED leaders seemed to view self-

557 regulation as a means of collaborating with formal regulatory agencies. NAPPMED leaders also

558 expressed interest in working with and being considered part of the formal health system.

\section{Discussion}

561 This study describes the extent to which PPMVs are embedded in networks of fellow drug

562 retailers, health professionals, and personal contacts that they rely on for different types of

563 support used to deal with daily encounters in their often tenuous position as informal healthcare

564 providers. The diversity of PPMVs' networks stems from their dual roles as health providers and

565 micro-entreprenuers, and the results thus speak to the largely separate literatures on the social

566 networks of both groups. On the one hand, our findings on the importance of personal networks

567 as a source of financial support in the absence of access to formal credit mechanisms echo those

568 on other types of microenterprises in Sub-Saharan Africa settings (Lyon, 2000; Zuwarimwe and

569 Kirsten, 2010). In terms of the emerging literature specifically on the networks of informal health

570 providers, we similarly find that continued relationships with training mentors are an important

571 source of support for PPMVs, and thus an important domain for understanding influences on

572 informal providers' practices (George and Iyer, 2013). On the other hand, we find little evidence

573 of network ties between PPMVs and drug detailers or pharmaceutical representatives, who have

574 been found to be sources of information for informal providers in other settings (Ecks and Basu, 
575 2014; Rahman et al., 2009 cited in Bloom et al. 2011). This may be related to the weakness of

576 pharmaceutical supply chains in our rural study sites.

578 While we find that PPMVs are embedded in networks with each other, as well as with medical

579 professionals, similar to other contexts (Ecks and Basu, 2014; George and Iyer, 2013), our results

580 also suggest that the types of social capital accessed through these ties may be important for

581 understanding their influence on PPMVs' practice. Much of PPMVs' support networks were

582 informal, including the connections to local health providers, and established through individual

583 relationships rather than formalized through the health system. For respondents, these ties

584 constituted a form of linking social capital with formally recognized medical personnel in the

585 health system, through which they could access informational support that helped them to serve

586 their customers. As noted above, the presence of positive linking capital between service

587 providers and their beneficiaries may help to ensure that services actually meet beneficiaries'

588 needs (Szreter and Woolcock, 2004). The dynamics between PPMV respondents and their

589 professional medical contacts further suggests that linking capital between different levels of

590 service providers may be important for responsive service delivery, for example by making

591 medical knowledge more available to low-level providers, or encouraging appropriate referral

592 practices. Linking social capital may be particularly important in contexts, such as the health

593 system in rural Nigeria, where service provision is fragmented and includes a range of actors

594 who are not connected by institutional structures to support quality and continuity of service

595 delivery. In combination with the fact that access to social capital has been shown to improve the

596 performance of other types of microenterprises in Sub-Saharan Africa (Barr, 2000; Fafchamps

597 and Minten, 2002; Zuwarimwe and Kirsten, 2010), this suggests that fostering more formalized 
598 linking social capital between PPMVs and health professionals may be one mechanism for

599 encouraging improved health practices on a broader and more sustainable basis.

600

601 Respondents' ties to other PPMVs through personal relationships and institutional membership

602 in NAPPMED were characterized by bonding social capital. In addition, linking capital

603 connected rank-and-file NAPPMED members with their organizational leadership through the

604 association's hierarchical structure, which provided respondents with access to a range of

605 instrumental and informational support. However, the extent to which NAPPMED leaders also

606 established informal, mentoring relationships with their members, such as a father-like

607 relationship that was characterized by bonding capital and the provision of emotional support,

608 influenced the depth of the association's role in providing support to its members. In wards

609 where these overlaying informal, bonding ties were not as strong, members appeared to rely less

610 on NAPPMED to access informational and instrumental support. This finding agrees with the

611 argument that organizations in which informal ties overlay the formal structure may be more

612 effective in achieving organizational goals (Oh et al., 2004), and also suggests that they may be

613 more able to influence the behaviors of their members, whether the influence exerted through

614 these informal ties takes a constructive or a more constraining form.

615

616 In addition to the specific instances of support that PPMVs recounted receiving, their networks

617 played a broader role in reinforcing the bounds of PPMV practice through what we term

618 reputational support. The broad reminders of 'good' PPMV practice were to some degree a form

619 of appraisal support in that they provided respondents with a set of guidelines against which they

620 were meant to judge their own practice. At the same time, and particularly when conveyed by 
621 more senior PPMVs, these guidelines were meant to protect the reputation of the PPMV

622 profession as law-abiding providers of health services. Reputational support was thus not only

623 given to individuals, but also formed the basis of a collective appraisal support, and was

624 understood by respondents to be provided based on altruistic sentiments. Reputational support

625 may thus have potential to help curtail poor service delivery practices in an environment where

626 regulatory enforcement is weak and mistrust of regulatory agencies is high. This may be

627 particularly effective if NAPPMED could be leveraged to provide a more consistent level of

628 support to its members, including enforcing scope of practice limitations that can both enhance

629 the reputation of the organization and the PPMV profession while improving the quality and 630 safety of health services provided by PPMVs.

631

632 Several limitations should be considered when interpreting our results. First, because we used a 633 non-probability sampling method, care should be taken in generalizing the findings, particularly

634 given the diversity of the PPMV sector throughout Nigeria. We did not interview the contacts

635 that respondents identified, and are unable to describe their motivations for providing this

636 support or verify their perceived support roles. In addition, we did not interview state or national

637 level NAPPMED officials, who may have a broader perspective on PPMVs' positioning within

638 the health system and in relation to regulatory agencies. While respondents' answers, particularly

639 regarding adherence to scope of practice, may have been influenced by social desirability, the

640 fact that many respondents self-reported carrying out illegal practices suggests that many were

641 forthcoming. Finally, we were not able to link respondents' discussions of their networks to the

642 quality of their health practices or business viability. This would be a useful line of further

643 inquiry; for example, a small number of PPMVs reported few or no contacts on whom they 
644 relied for support. This may impact their health or business practices, but because the study was

645 not designed to measure these practices outside of self-reported strategies for accessing support

646 we are unable to assess how. A larger study is needed to both further assess the influence of

647 variation in PPMVs' networks by their sociodemographic characteristics or training, and the

648 relationship between network characteristics and service delivery or business outcomes. Future

649 research should further explore the potential for interventions based on building social capital to 650 improve service delivery among informal healthcare providers.

\section{Conclusion}

653 This is the first study to examine the support networks that PPMVs in Nigeria rely on in running 654 their shops, demonstrating that PPMVs are embedded in complex informal and formal networks 655 with other drug sellers and health professionals, through which they access a variety of forms of 656 support. In addition to providing specific forms of informational and instrumental support,

657 PPMVs' networks continually reinforce socially understood - if not legally or medically

658 sanctioned - definitions of the limits of PPMV practice through what we term reputational

659 support. The role of PPMVs' networks in encouraging practices that reduce the likelihood of 660 negative customer outcomes, as well as in providing assistance with customers' health concerns, 661 highlights the potential effect that linking capital between different levels of healthcare providers 662 may have on the quality of service delivery. Interventions that seek to improve the quality of 663 services provided by PPMVs should leverage these existing networks, including those created 664 through the NAPPMED organization, to reinforce change in health practices. 


\section{References}

Arrow, K.J., 1963. Uncertainty and the welfare economics of medical care. Am. Econ. Rev. 941973.

Barnes, J., Chandani, T., Feeley, R., 2008. Nigeria private sector health assessment. Private Sector Partnerships-One project, Abt Associates Inc., Bethesda, MD.

Barr, A., 2000. Social capital and technical information flows in the Ghanaian manufacturing sector. Oxf. Econ. Pap. 52, 539-559.

Beyeler, N., Liu, J., Sieverding, M., 2015. A systematic review of the role of proprietary and patent medicine vendors in healthcare provision in Nigeria. PloS One 10, e0117165.

Bloom, G., Standing, H., Lloyd, R., 2008. Markets, information asymmetry and health care: Towards new social contracts. Soc. Sci. Med. 66, 2076-2087.

Bloom, G., Standing, H., Lucas, H., Bhuiya, A., Oladepo, O., Peters, D.H., 2011. Making health markets work better for poor people: The case of informal providers. Health Policy Plan. $26, \mathrm{i} 45-\mathrm{i} 52$.

Brieger, W.R., Osamor, P.E., Salami, K.K., Oladepo, O., Otusanya, S.A., 2004. Interactions between patent medicine vendors and customers in urban and rural Nigeria. Health Policy Plan. 19, 177-182.

Cross, J., MacGregor, H.N., 2010. Knowledge, legitimacy and economic practice in informal markets for medicine: A critical review of research. Soc. Sci. Med. 71, 1593-1600.

Ecks, S., Basu, S., 2014. "We always live in fear" antidepressant prescriptions by unlicensed doctors in India. Cult. Med. Psychiatry 38, 197-216.

Fafchamps, M., Minten, B., 2002. Returns to social network capital among traders. Oxf. Econ. Pap. 54, 173-206.

Fajola, A., Asuzu, M.C., Owoaje, E.T., Asuzu, C.C., Ige, O.K., Oladunjoye, O.O., Asinobi, A., 2011. A Rural-Urban Comparison of Client-Provider Interactions in Patent Medicine Shops in South West Nigeria. Int. Q. Community Health. Educ. 32, 195-203.

Ferlander, S., 2007. The importance of different forms of social capital for health. Acta Sociol. $50,115-128$.

George, A., Iyer, A., 2013. Unfree markets: Socially embedded informal health providers in northern Karnataka, India. Soc. Sci. Med. 96, 297-304.

House, J.S., 1981. Work stress and social support. Addison-Wesley Pub. Co., Reading, Mass.

Lyon, F., 2000. Trust, networks and norms: The creation of social capital in agricultural economies in Ghana. World Dev. 28, 663-681.

Oh, H., Chung, M.-H., Labianca, G., 2004. Group social capital and group effectiveness: The role of informal socializing ties. Acad. Manage. J. 47, 860-875.

Oladepo, O., Salami, K.K., Adeoye, B.W., Oshiname, F., Ofi, B., Oladepo, M., Ogunbemi, O., Lawal, A., Brieger, W.R., Bloom, G., Peters, D., 2007. Malaria treatment and policy in three regions in Nigeria: The role of patent medicine vendors (Working Paper No. No. 1). Future Health Systems.

Onwujekwe, O., Onoka, C., Uzochukwu, B., Hanson, K., 2011. Constraints to universal coverage: inequities in health service use and expenditures for different health conditions and providers. Int J Equity Health 10, 50.

Oyeyemi, A.S., Ogunnowo, B.E., Odukoya, O.O., 2014. Patent Medicine Vendors in Rural Areas of Lagos Nigeria: Compliance with Regulatory Guidelines and Implications for Malaria Control. Trop. J. Pharm. Res. 13, 163-169. 
Rahman, H., Agarwal, S., Tuddenham, A., 2009. Whose prescription is this? Exploring effects of drug detailing on village doctors (Unpublished manuscript). Johns Hopkins School of Public Health.

Shah, N.M., Brieger, W.R., Peters, D.H., 2011. Can interventions improve health services from informal private providers in low and middle-income countries? A comprehensive review of the literature. Health Policy Plan. 26, 275-287.

Sloan, F.A., 2000. Not-for-profit ownership and hospital behavior. Handb. Health Econ. 1, $1141-1174$.

Sudhinaraset, M., Ingram, M., Lofthouse, H.K., Montagu, D., 2013. What is the role of informal healthcare providers in developing countries? A systematic review. PLoS ONE 8, e54978.

Szreter, S., Woolcock, M., 2004. Health by association? Social capital, social theory, and the political economy of public health. Int. J. Epidemiol. 33, 650-67.

Ujuju, C., Adebayo, S.B., Anyanti, J., Oluigbo, O., Muhammad, F., Ankomah, A., 2014. An assessment of the quality of advice provided by patent medicine vendors to users of oral contraceptive pills in urban Nigeria. J. Multidiscip. Healthc. 7, 163-171.

Wafula, F.N., Miriti, E.M., Goodman, C.A., 2012. Examining characteristics, knowledge and regulatory practices of specialized drug shops in Sub-Saharan Africa: a systematic review of the literature. BMC Health Serv. Res. 12, 223.

Woolcock, M., 1998. Social Capital and Economic Development: Toward a Theoretical Synthesis and Policy Framework. Theory Soc. 27, 151-208.

Zuwarimwe, J., Kirsten, J., 2010. The role of social networks in development of small-scale enterprises in the Chimanimani district of Zimbabwe. Agrekon 49, 17-38. 
Table 1: Demographic and socioeconomic characteristics of the sample

\begin{tabular}{|c|c|c|}
\hline & $\mathrm{N}$ & $\%$ \\
\hline \multicolumn{3}{|c|}{ Current NAPPMED registration } \\
\hline Yes & 67 & 98.5 \\
\hline No & 1 & 1.5 \\
\hline \multicolumn{3}{|c|}{ Highest education completed } \\
\hline Primary & 6 & 9.5 \\
\hline Secondary & 39 & 61.9 \\
\hline Tertiary or higher & 18 & 28.6 \\
\hline \multicolumn{3}{|c|}{ Formal medical training } \\
\hline None & 45 & 66.2 \\
\hline Some & 19 & 27.9 \\
\hline \multicolumn{3}{|l|}{ Gender } \\
\hline Female & 26 & 38.2 \\
\hline Male & 38 & 55.9 \\
\hline Age - Mean (Range) & 34.8 & \\
\hline \multicolumn{3}{|l|}{ Religion } \\
\hline Christian & 47 & 69.1 \\
\hline Muslim & 16 & 23.5 \\
\hline \multicolumn{3}{|l|}{ Tribe } \\
\hline Igala & 9 & 13.2 \\
\hline Igbo & 30 & 44.1 \\
\hline Yoruba & 22 & 32.4 \\
\hline Other & 2 & 2.9 \\
\hline Total & 68 & 100.0 \\
\hline
\end{tabular}


Table 2: Characteristics of responding PPMVs' support networks

\begin{tabular}{|c|c|c|c|}
\hline & $\begin{array}{l}\text { Learn about new } \\
\text { medicine }\end{array}$ & $\begin{array}{l}\text { Advice on a difficult } \\
\text { pediatric case }\end{array}$ & $\begin{array}{c}\text { Help with a } \\
\text { problem in the } \\
\text { shop }\end{array}$ \\
\hline Total number of contacts & 123 & 87 & 105 \\
\hline $\begin{array}{l}\text { Mean number of contacts } \\
\text { (SD) }\end{array}$ & $1.8(1.1)$ & $1.3(1.1)$ & $1.5(1.1)$ \\
\hline \multicolumn{4}{|l|}{ Number of contacts $(\%)$} \\
\hline 0 & 16.2 & 33.9 & 22.0 \\
\hline 1 & 22.1 & 25.0 & 26.5 \\
\hline 2 & 26.4 & 20.6 & 26.5 \\
\hline 3 & 35.3 & 20.6 & 25.0 \\
\hline \multicolumn{4}{|l|}{ Profession of contact $(\%)$} \\
\hline Medical Professional & 22.8 & 59.8 & 14.3 \\
\hline PPMV (all) & 38.2 & 32.2 & 45.7 \\
\hline$P P M V$ & 22.8 & 13.8 & 16.2 \\
\hline PPMV Master & 7.3 & 12.6 & 10.5 \\
\hline NAPPMED Chairman & 8.1 & 5.8 & 19.1 \\
\hline Other drug retailer/wholesaler & 35.8 & 3.5 & 7.6 \\
\hline Other & 3.2 & 4.6 & 32.4 \\
\hline \multicolumn{4}{|l|}{ Relationship to contact (\%) } \\
\hline Professional contact & 68.3 & 63.2 & 57.7 \\
\hline Friend & 14.6 & 17.2 & 9.6 \\
\hline Relative & 14.6 & 13.8 & 27.9 \\
\hline Other & 2.4 & 5.8 & 4.7 \\
\hline \multicolumn{4}{|l|}{ Contact lives in community (\%) } \\
\hline Yes & 21.3 & 43.0 & 46.1 \\
\hline No & 78.7 & 57.0 & 53.9 \\
\hline
\end{tabular}

Note: Total number of respondents is 68 